This is an author produced version of a paper published in Chemistry - a European journal.

This paper has been peer-reviewed but may not include the final publisher proof-corrections or pagination.

Citation for the published paper:

Ingmar Persson, Paola D’Angelo \& Daniel Lundberg. (2016) Hydrated and Solvated Tin(II) Ions in Solution and the Solid State, and a Coordination Chemistry Overview of the $\mathrm{d}(10) \mathrm{s}(2)$ Metal Ions. Chemistry - a European journal. Volume: 22, Number: 51, pp 18583-18592. http://dx.doi.org/10.1002/chem.201603904.

Access to the published version may require journal subscription.

Published with permission from: Wiley.

Standard set statement from the publisher:

"This is the peer reviewed version of the following article: I. Persson, P. D'Angelo, D. Lundberg, Chem. Eur. J. 2016, 22, 18583, which has been published in final form at http://dx.doi.org/10.1002/chem.201603904 . This article may be used for noncommercial purposes in accordance with Wiley Terms and Conditions for SelfArchiving."

Epsilon Open Archive http://epsilon.slu.se 


\title{
Hydrated and Solvated Tin(II) Ions in Solution and Solid State, and a Coordination Chemistry Overview of the $\mathrm{d}^{10} \mathrm{~s}^{\mathbf{2}}$ Metal Ions
}

\author{
Ingmar Persson, ${ }^{\mathrm{a} *}$ Paola D’Angelo ${ }^{\mathrm{b}}$ and Daniel Lundberg ${ }^{\mathrm{a}}$
}

a Department of Chemistry and Biotechnology, Swedish University of Agricultural Sciences, P.O. Box 7015, SE-750 07 Uppsala, Sweden.

b Dipartimento di Chimica, Universitá di Roma “La Sapienza”, P.le A. Moro 5, I-00185 Roma, Italy.

\section{Synopsis}

The coordination chemistry of tin(II) is strongly affected by the partially filled $\operatorname{Sn}(5 s)$ ligand(n $p)$ anti-bonding orbital causing structural distortions including a large void in the coordination sphere. The mean tin-ligand atom bond distance varies largely with type of ligand atom, even within the same coordination number. The actual coordination number and bond angles of tin(II) complexes seems to depend on tin-ligand bond character.

\section{Graphic Entry}

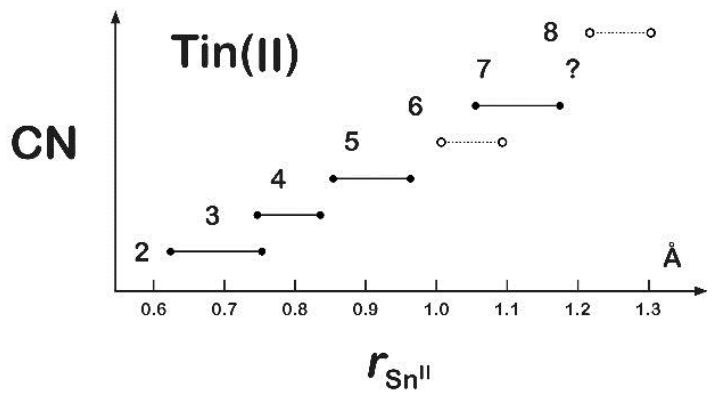




\begin{abstract}
The coordination chemistry of $\mathrm{d}^{10} \mathrm{~s}^{2}$ metal ions is strongly affected by an, at least partially, occupied $\mathrm{d}^{10} \mathrm{~s}^{2}$ metal ion-ligand anti-bonding orbital, which may cause a void in the coordination sphere due to repulsion between the electrons in the anti-bonding orbital on the metal ion and those on the ligands. The character of the formed $\mathrm{d}^{10} \mathrm{~s}^{2}$ metal ion-ligand atom bond plays an important role for the electron density in the anti-bonding orbital and thereby also for the coordination chemistry. The hydrated $\operatorname{tin}(\mathrm{II})$ ion, $\left[\mathrm{Sn}\left(\mathrm{H}_{2} \mathrm{O}\right)_{3}\right]^{2+}$, and the trishydroxidostannate ion, $\left[\mathrm{Sn}(\mathrm{OH})_{3}\right]^{-}$, display very different mean Sn-O bond distances, 2.21 and $2.08 \AA$, and O-Sn-O angles, ca. 78 and $90^{\circ}$, respectively, in both solid state and solution. By increasing the covalency in the tin(II)-ligand bonds, the repulsion decreases and higher coordination numbers are obtained, as seen in the solvated dimethylsulfoxide and $N, N$-dimethylthioformamide solvated tin(II) ions, both five-coordinate in square-pyramidal fashion.
\end{abstract}




\section{Introduction}

In accordance with the general rule concerning oxidation states of the heavier $p$-block elements, the group 14 elements tin and lead display the oxidation states $+\mathrm{II}$ and $+\mathrm{IV}$ with preference for $+\mathrm{II}$ for lead and $+\mathrm{IV}$ for tin. Tin displays stable chemistry for both oxidation states in water, while the chemistry of lead is dominated by lead(II) as lead(IV) compounds are strong oxidants in aqueous systems, being spontaneously reduced to lead(II) under formation of oxygen gas. The tendency of the heavier main group elements to adopt an oxidation state two steps below being fully oxidized one has been attributed to the "inert pair" effect. ${ }^{[1]}$ According to valence bond theory an inert electron-pair can occupy a hybrid orbital formed by mixing the n $s$ and $\mathrm{n} p$ orbitals on the metal ion and as such become stereo-chemically active. However, according to molecular orbital theory the classical concept of $5 s / 5 p$ orbital hybridization on the tin(II) ion is regarded as incorrect. Instead the stereo-chemical activity is the result of tin(II) antibonding orbital-donor atom interactions. ${ }^{[2]}$ The character of the formed tin(II)-ligand atom bond plays an important role for the electron density in the anti-bonding orbital and thereby on the size of the created void, a so-called gap, in the coordination sphere of tin(II). With donor atoms forming mainly electrostatic interactions, such as oxygen donor ligands, the antibonding $\operatorname{Sn}(5 s)$ ligand(n $p)$ orbital couple with the $\operatorname{Sn}(5 p)$ one. This coupling can only take place when the donor atom of the ligand can generate a significant number of $\operatorname{Sn}(5 s)$ states close to the Fermi level as the large energy difference between $\operatorname{Sn}(5 s)$ and $\operatorname{Sn}(5 p)$ prevents them to form direct coupling. ${ }^{[2-4]}$ On the other hand, ligands forming mainly covalent bonds result in weaker antibonding $\operatorname{Sn}(5 s)$ ligand atom(np)-Sn(5p) coupling causing a gradual decrease in the electron density in the antibonding orbitals with increasing covalency of the Sn-ligand bond seen e.g. in a regular octahedral configuration of telluride ions around tin(II) in solid SnTe. ${ }^{[5]}$ Two general structural types of tin(II) complexes are identified, the very uncommon holo-directed one without a gap in the coordination sphere, only observed in solid SnTe, ${ }^{[5]}$ and the totally dominating hemi-directed one with a gap in the coordination sphere, as proposed by Shimoni-Livny et al. for lead(II), ${ }^{[6]}$ but applicable for other $\mathrm{d}^{10} \mathrm{~s}^{2}$ metal complexes as well. The principles of the stereo-chemical activity of $\mathrm{d}^{10} \mathrm{~s}^{2}$ metal ions and the role of the anti-bonding metal-ligand molecular orbitals have been described and discussed in a number of publication the last ten years, ${ }^{[2-4,7-10]}$ and will not be further discussed in this paper.

The structures of coordination compounds and complexes of tin(II) with oxygen donor ligands in the solid state are very diverse with a broad range of coordination numbers, CNs, from 
2 to $8,{ }^{[11,12]}$ Table $S 1$. All these structures, including those with the highest coordination numbers, have a visible gap in the coordination sphere, thus, all can be regarded as hemi-directed. This gap is very significant for compounds and complexes with low coordination numbers, $2 \leq \mathrm{CN} \leq 4$, with mean O-Sn-O bond angles typically at or below $90^{\circ}$, Table S1. Furthermore, the unusually large mean $\mathrm{Sn}-\mathrm{O}$ bond distance distribution within the same coordination number is striking, and will be discussed in more detail, see Results and Discussion.

Despite the large number of coordination compounds of tin(II) reported in the solid state, ${ }^{[11,12]}$ Table S1, the knowledge about its coordination chemistry in solution is extremely limited. The only two investigations of the structure of the hydrated tin(II) ion in aqueous solution were both reported more than 30 years ago and are quite uncertain. A large angle X-ray scattering (LAXS) study reported that tin(II) binds 2-3 water molecules at $2.3 \AA$, ${ }^{[13]}$ and a combined EXAFS and LAXS study reported that tin(II) binds 3-4 water molecules at 2.25-2.34 $\AA$, with a significant gap in the coordination shell. ${ }^{[14]}$ More recently, two theoretical simulations made by Rode et al. have reported that the hydrated tin(II) ion binds eight water molecules in asymmetrical bond distribution at $2.39 \AA .{ }^{[15,16]}$ The first crystallographic study of a compound with a hydrated tin(II) ion, $\left[\mathrm{Sn}\left(\mathrm{H}_{2} \mathrm{O}\right)_{3}\right]\left(\mathrm{ClO}_{4}\right)_{2}$, was recently reported. ${ }^{[17]}$ In this structure tin(II) binds three water molecules at 2.200 $\mathrm{A}$, and the $\mathrm{O}-\mathrm{Sn}-\mathrm{O}$ bond angles are $76.9^{\circ}$. Thus, the water molecules occupy only a small fraction of the coordination sphere, less than $15 \%$, showing that the anti-bonding orbital has a uniquely large influence on the coordination geometry. This is the only homoleptic tin(II) complex with neutral and monodentate ligands reported so far.

The tin(II) ion undergoes hydrolysis even in weak acidic aqueous solution. The primary hydrolysis product is the trinuclear $\left[\mathrm{Sn}_{3}(\mathrm{OH})_{4}\right]^{2+}$ complex with minor presence of mono- and dinuclear complexes, $[\mathrm{Sn}(\mathrm{OH})]^{+}$and $\left[\mathrm{Sn}_{2}(\mathrm{OH})_{2}\right]^{2+} \cdot{ }^{[18]}$ The structure of the trishydroxidostannate(II), $\left[\mathrm{Sn}(\mathrm{OH})_{3}\right]^{-}$complex in hyper-alkaline aqueous solution was reported recently. ${ }^{[19]}$ The SnO bond distance in the $\left[\mathrm{Sn}(\mathrm{OH})_{3}\right]^{-}$complex, $2.080 \AA$, is in excellent agreement with the same complex in the solid state, $\mathrm{Na}_{4}\left[\mathrm{Sn}(\mathrm{OH})_{3}\right]_{2}\left[\mathrm{Sn}_{2} \mathrm{O}(\mathrm{OH})_{4}\right],{ }^{[20]}$ mean Sn-O bond distance, $2.080 \AA$, thus, remarkably shorter than in the hydrated tin(II) ion mentioned above.

The aim of this study is to get a deeper insight into the coordination chemistry of the $\mathrm{d}^{10} \mathrm{~s}^{2}$ metal ions, focusing on tin(II), which is the least studied one in solution. Apart from the old and highly uncertain data for the hydrate and some hydrolysis products in aqueous solution ${ }^{[13,14,19]}$ no other experimental structural information is available for solvated tin(II) ions in any other solvent. Here, new experimental LAXS, EXAFS and XANES data are reported on the hydrated 
tin(II) ion in aqueous solution, and the structure of $\left[\mathrm{Sn}\left(\mathrm{H}_{2} \mathrm{O}\right)_{3}\right]\left(\mathrm{ClO}_{4}\right)_{2}$ has been re-determined and confirmed, Table S2. Furthermore, the structure of the dimethylsulfoxide (dmso) solvated tin(II) ion has been determined in solution and solid state, while the structure of the $N, N$ dimethylthioformamide (dmtf) solvated tin(II) ion has been determined in solution as the attempts to crystallization failed. The sulfur donor solvent dmtf may influence the coordination chemistry of tin(II) in a different way than the oxygen donor solvents forming bonds with a higher degree of covalency than oxygen donor solvents, seen in its significantly larger $D_{\mathrm{S}}$ number, 52, than for dmso (27.5) and water (18). ${ }^{[21]}$ The coordination chemistry of the $\mathrm{d}^{10} \mathrm{~s}^{2}$ metal ions will be summarized as they are the only metal ions whose coordination chemistry is strongly affected by anti-bonding metal-ligand orbitals.

\section{Results and Discussion}

\section{The Hydrated Tin(II) Ion}

The crystal structure of $\left[\mathrm{Sn}\left(\mathrm{H}_{2} \mathrm{O}\right)_{3}\right]\left(\mathrm{ClO}_{4}\right)_{2}, \mathbf{1}$, reported recently, ${ }^{[17]}$ has been confirmed in this study with the same structure parameters within the estimated errors. The structure of the hydrated tin(II) ion in $\mathbf{1}$ is shown in Figure 1, selected bond distances and angles are given in Table 1, the .cif file of $\mathbf{1}$ in Table S2 and a plot of the packing of $\mathbf{1}$ in the unit cell in Figure S1. The EXAFS spectra of the hydrated tin(II) ion in aqueous solution and $\mathbf{1}$ are almost identical, Figure 2, showing that the hydrated tin(II) ion has the same structure in aqueous solution as the $\left[\mathrm{Sn}\left(\mathrm{H}_{2} \mathrm{O}\right)_{3}\right]^{2+}$ unit in $\mathbf{1}$. The structure parameters of the hydrated tin(II) ion from the EXAFS studies of $\mathbf{1}$ and in aqueous solution are given in Table 2, and the fit of the experimental EXAFS data are shown in Figure S2.

The radial distribution function (RDF) from the LAXS experiment on the aqueous tin(II) perchlorate solution reveals four peaks at 1.45, 2.2, 2.9 and $4.15 \AA$, Figure 3 . The peak at $1.45 \AA$ corresponds to the $\mathrm{Cl}-\mathrm{O}$ bond distance within the perchlorate ion. The peaks at 2.2 and $4.15 \AA$ correspond to the first and second hydration sphere, and were refined to 2.206(6) and 4.126(9) $\AA$, respectively. The peak at $2.9 \AA$ corresponds to the mean $\mathrm{O}(-\mathrm{H}) \cdots \mathrm{O}$ distance in the aqueous bulk. The Sn-O distance is slightly longer in aqueous solution than in 1, seen in both EXAFS and LAXS data, due to more complete and efficient hydration including a second hydration sphere. The refined structure parameters are summarized in Table 3, the RDFs, the individual model contributions to the RDF and the fit of the experimental data are shown in Figure 3. 
Table 1. Selected bond lengths ( $⿱$ ) and angles (deg) in 1, 2 and 3. Mean values are given in italic by type as discussed in the text, and a mean for all distances within parentheses.

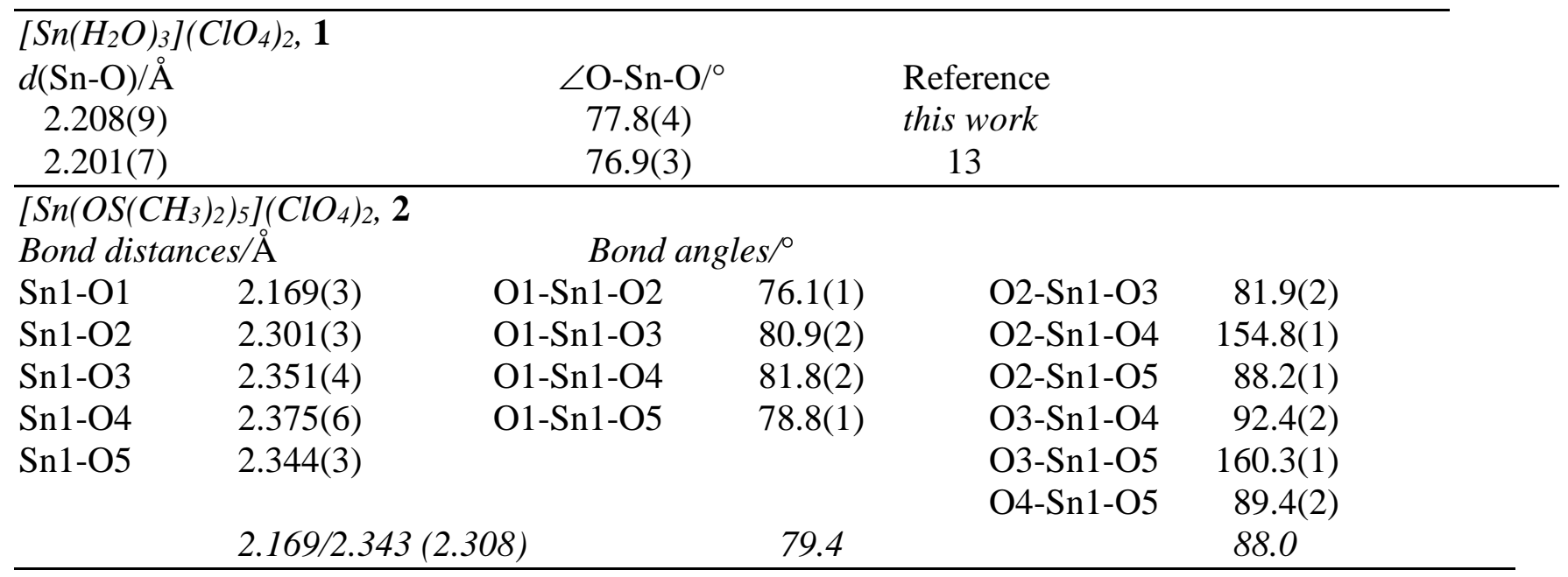
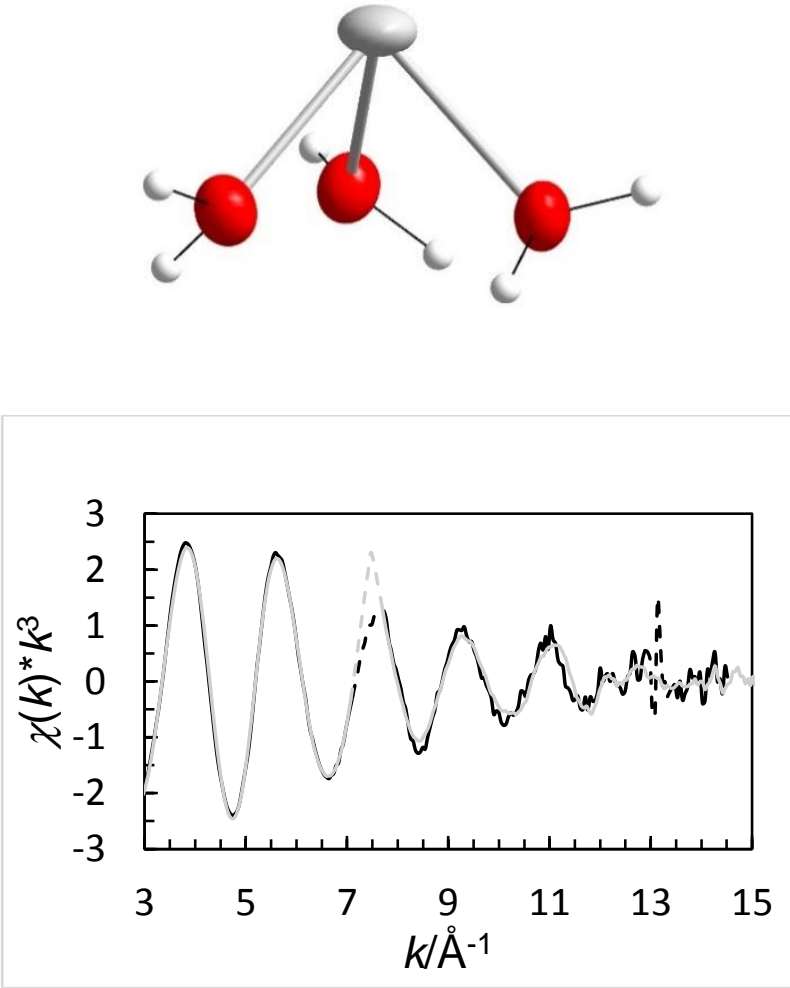

Figure 1. Structure of the $\left[\mathrm{Sn}\left(\mathrm{H}_{2} \mathrm{O}\right)_{3}\right]^{2+}$ unit in $\mathbf{1}$, with a gap covering more than a hemisphere. Thermal elipsoids (at $40 \%$ probability) are shown for all non-hydrogen atoms.

Figure 2. Experimental EXAFS data solid 1 (black line) and the hydrated tin(II) ion aqueous solution (grey line). The sections with dashed lines represents regions with glitches not included in the calculations.

The analysis of the XANES region of 1 and aqueous solution of tin(II) perchlorate shows a very good fit with a three-coordination and $\mathrm{O}-\mathrm{Sn}-\mathrm{O}$ bond angles close to $78^{\circ}$, Figure 4 . The Sn-O 
bond distances are systematically ca. $0.04 \AA$ shorter than in the other structure methods applied. The existence of systematic errors of this order of magnitude in the analysis of the XANES data has been pointed out in previous works, and it is probably due to the longer mean path of the photoelectron in the XANES energy range with respect to the EXAFS approach, and to the use of a phenomenological approach to deal with inelastic losses. ${ }^{[22,23]}$

Table 3. Mean bond distances, $d / \AA$, number of distances, $N$, temperature coefficients, $b / \AA^{2}$, and the half-height full width, $l / \AA$, in the LAXS studies of the solvated tin(II) ion in aqueous, dmso and dmtf solution at room temperature.

\begin{tabular}{llrllc}
\hline Species & Interaction & $N$ & $d$ & $b$ & $l$ \\
\hline \multicolumn{7}{l}{ Tin(II) perchlorate } & in water, 1.70 & $\mathrm{~mol} \cdot \mathrm{dm}^{-3}$ & & & \\
{$\left[\mathrm{Sn}\left(\mathrm{OH}_{2}\right)_{3}\right]^{2+}$} & $\mathrm{Sn}-\mathrm{O}$ & 3 & $2.206(2)$ & $0.0067(3)$ & $0.116(2)$ \\
& $\mathrm{Sn} \cdots \mathrm{O}_{\mathrm{II}}$ & 12 & $4.126(3)$ & $0.0143(3)$ & $0.169(2)$ \\
$\mathrm{ClO}_{4}^{-}(\mathrm{aq})$ & $\mathrm{Cl}-\mathrm{O}$ & 4 & $1.453(4)$ & $0.0044(2)$ & $0.063(3)$ \\
& $(\mathrm{Cl}-\mathrm{O} \cdots \mathrm{O}$ & 4 & $3.028(6)$ & $0.0248(11)$ & $0.223(5)$ \\
& $\mathrm{Cl}-(\mathrm{O}) \cdots \mathrm{O}$ & 4 & $3.697(5)$ & $0.0445(10)$ & $0.0298(4)$ \\
Water bulk & $\mathrm{O} \cdots \mathrm{O}$ & 2 & $2.890(3)$ & $0.0170(5)$ & $0.0184(3)$
\end{tabular}

Tin(II) perchlorate in dmso, $1.30 \mathrm{~mol} \cdot \mathrm{dm}^{-3}$

$\begin{array}{rlllll}{\left[\mathrm{Sn}(\mathrm{dmso})_{5}\right]^{2+}} & \mathrm{Sn}-\mathrm{O} & 1 & 2.204(9) & 0.0069(9) & 0.117(8) \\ & \mathrm{Sn}-\mathrm{O} & 4 & 2.345(6) & 0.0082(5) & 0.128(4) \\ & \mathrm{Sn} \cdots \mathrm{S} & 1 & 3.383(10) & 0.022(2) & 0.21(1) \\ \mathrm{Sn} \cdots \mathrm{S} & 4 & 3.582(4) & 0.0324(7) & 0.255(2)\end{array}$

Tin(II) trifluoromethanesulfonate in dmtf, $1.00 \mathrm{~mol} \cdot \mathrm{dm}^{-3}$

$\begin{array}{rlllll}{\left[\mathrm{Sn}(\mathrm{dmtf})_{5}\right]^{2+}} & \mathrm{Sn}-\mathrm{S} & 1 & 2.698(4) & 0.0076(6) & 0.123(5) \\ & \mathrm{Sn}-\mathrm{S} & 4 & 2.898(4) & 0.0233(4) & 0.216(2) \\ & \mathrm{Sn} \cdots \mathrm{C} & 1 & 3.51(2) & 0.014(2) & 0.17(2) \\ & \mathrm{Sn} \cdots \mathrm{C} & 4 & 3.656(8) & 0.035(2) & 0.26(1)\end{array}$



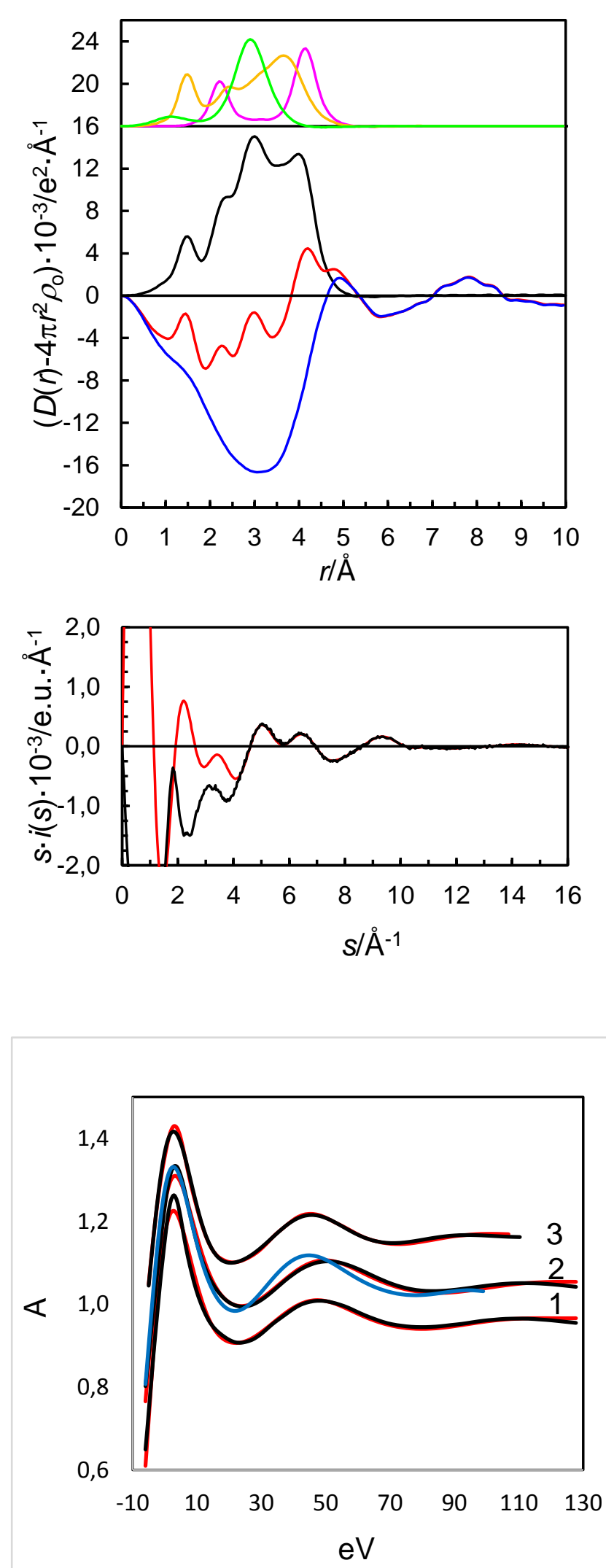

Figure 3. (Top) LAXS radial distribution curves for a $1.70 \mathrm{~mol} \cdot \mathrm{dm}^{-3}$ aqueous solution of tin(II) perchlorate. Upper part: Separate model contributions (offset: 16) of the hydrated tin(II) ion (cerise line), the hydrated perchlorate ion (orange line) and aqueous bulk (green line). (Middle) Experimental RDF: $D(r)-4 \mathrm{p} r^{2} \rho_{\text {o }}$ (black line); sum of model contributions (black line); difference (blue line). (Bottom) Reduced LAXS intensity functions $s \cdot i(s)$ (black line); model $s \cdot i_{\text {calc }}(s)$ (red line).

Figure 4. Experimental XANES data (black line) and modelled XANES data by MXAN (red line) for $1 /$ the hydrated tin(II) ion in $\mathbf{1}$, $2 /$ the hydrated tin(II) ion in aqueous solution, the blue line is the best fit of a fivecoordinate model, $3 /$ the dimethylsulfoxide solvated tin(II) ion in $\mathbf{2}$. The structure and energy parameters given in Table 4. 
Table 4. Non-structural and structural parameters obtained from the minimization procedures. The refined non-structural parameters are the Fermi energy level (with respect to the threshold energy), $E_{\mathrm{F}} / \mathrm{eV}$, the threshold energy, $E_{\mathrm{o}} / \mathrm{eV}$, the energy and amplitude of the plasmon, $E_{\mathrm{s}} / \mathrm{eV}$ and $A_{\mathrm{s}}$, respectively, core-hole broadening, $\Gamma_{\mathrm{c}} / \mathrm{eV}$, and the width of the Gaussian convolution function accounting for the experimental resolution, $\Gamma_{\exp } / \mathrm{eV}$, and the refined structural parameters are $\mathrm{Sn}-\mathrm{O}$ bond distance, $d(\mathrm{Sn}-\mathrm{O}) / \AA$, O-Sn-O bond angle, $\angle(\mathrm{OSnO}) /{ }^{\circ}$, Sn--S bond distance, $d(\mathrm{Sn}-\mathrm{S}) / \AA$, and $\mathrm{Sn}-\mathrm{O}-\mathrm{S}$ bond angle, $\angle(\mathrm{SnOS}) /^{\circ}$, while the coordination number around tin, $N(\mathrm{Sn}-\mathrm{O})$, was fixed.

Non-structural parameters

\begin{tabular}{lrrrrrr} 
& $E_{\mathrm{F}}$ & $E_{\mathrm{o}}$ & \multicolumn{1}{c}{$E_{\mathrm{s}}$} & \multicolumn{1}{c}{$A_{\mathrm{s}}$} & $\Gamma_{\mathrm{c}}$ & $\Gamma_{\exp }$ \\
\hline $\mathrm{Sn}^{2+} / \mathrm{aq}$ & -4.98 & 29207.7 & 14.60 & 6.57 & 9.05 & 3.67 \\
$\mathbf{1}$ & -5.01 & 29207.9 & 17.60 & 7.70 & 9.05 & 3.67 \\
{$\left[\mathrm{Sn}(\mathrm{OH})_{3}\right]^{-} / \mathrm{aq}$} & -8.49 & 29208.7 & 9.89 & 12.37 & 8.95 & 3.67 \\
$\mathbf{2}$ & -2.27 & 29212.0 & 15.89 & 11.69 & 11.64 & 4.78
\end{tabular}

Structural parameters

\begin{tabular}{lccccccc} 
& $d(\mathrm{Sn}-\mathrm{O})$ & $N(\mathrm{Sn}-\mathrm{O})$ & $\angle(\mathrm{OSnO})$ & $d(\mathrm{~S}-\mathrm{H})$ & $\angle(\mathrm{SnOH})$ & $d(\mathrm{Sn}--\mathrm{S})$ & $\angle(\mathrm{SnOS})$ \\
\hline $\mathrm{Sn}^{2+} / \mathrm{aq}$ & 2.123 & 3 & 77.4 & 2.815 & 127.8 & & \\
$\mathbf{1}$ & 2.165 & 3 & 80.5 & 2.885 & 130.7 & & \\
{$\left[\mathrm{Sn}(\mathrm{OH})_{3}\right]^{-/ \mathrm{aq}}$} & 2.043 & 3 & 89.7 & 2.531 & 109.5 & & 134.5 \\
& 2.063 & 3 & 89.7 & 2.549 & 109.5 & & 3.32 \\
$\mathbf{2}$ & 2.192 & 1 & 90 & & & 3.415 & 125.5
\end{tabular}


A five-coordinated square pyramidal model, similar to the one found in the dmso solvate, vide infra, was also tested but the fit was significantly worse than for the three-coordinated model, Figure 4. The structural and non-structural parameters of the XANES fittings are summarized in Table 4.

The Sn-O bond distance in the hydrated tin(II) ion, $2.21 \AA$, is the longest $\mathrm{Sn}-\mathrm{O}$ bond distance reported for a three-coordinate tin(II) compound, ca. $0.13 \AA$ longer than in the trihydroxidostannate(II) complex, $\left[\mathrm{Sn}(\mathrm{OH})_{3}\right]^{-} \cdot{ }^{[19]}$ Furthermore, the O-Sn-O bond angles in the hydrated tin(II) ion are very small, ca. $78^{\circ}$, showing that the size requirements of the antibonding orbital is extensive.

\section{The trishydroxidostannate(II) ion in alkaline aqueous solution}

The Sn-O bond distance in the $\left[\mathrm{Sn}(\mathrm{OH})_{3}\right]^{-}$ion in alkaline aqueous solution ${ }^{[19]}$ and solid state $^{[20]}$ is $2.08 \AA$. The mean $\mathrm{O}-\mathrm{Sn}-\mathrm{O}$ bond angle in the $\left[\mathrm{Sn}(\mathrm{OH})_{3}\right]^{-}$complex in solid $\mathrm{Na}_{4}\left[\mathrm{Sn}(\mathrm{OH})_{3}\right]_{2}\left[\mathrm{Sn}_{2} \mathrm{O}(\mathrm{OH})_{4}\right]$ is $88.7^{\circ}$, while it was not possible to determine it from the EXAFS data. The fitting of the XANES region resulted in a Sn-O bond distance of $2.04 \AA, 0.04 \AA$ shorter than expected, vide supra, and a mean O-Sn-O bond angle of ca. $90^{\circ}$, Table 4 , which is in good agreement with the observation in the solid state. The fit of the XANES region is shown in Figure 4, and the refined non-structural and structural parameters are summarized in Table 4.

\section{Relationship between Sn-O bond distance and O-Sn-O bond angle in three-coordinate tin(II) complexes with oxygen donor ligands.}

The only two three-coordinate tin(II) complexes studied in aqueous solution, $\left[\mathrm{Sn}\left(\mathrm{H}_{2} \mathrm{O}\right)_{3}\right]^{2+}$ and $\left[\mathrm{Sn}(\mathrm{OH})_{3}\right]^{-}$, display a remarkable difference in both $\mathrm{Sn}-\mathrm{O}$ bond distance and $\mathrm{O}-\mathrm{Sn}-\mathrm{O}$ bond angle, not seen for any other metal ion system. For all metal ions other than the $\mathrm{d}^{10} \mathrm{~s}^{2}$ ones, the relationship between $\mathrm{M}-\mathrm{O}$ bond distance and coordination number is very strict and it is possible with good accuracy to predict the coordination number from the mean bond distance and vice versa. ${ }^{[24]}$ In order to shed light on the peculiar coordination chemistry of the tin(II) ion, all reported three-coordinated tin(II) complexes with oxygen donor ligands are summarized, Table S1. A scatter plot shows a weak relationship between Sn-O bond distance and O-Sn-O bond angle with increasing bond angle with decreasing Sn-O bond distance, Figure 5. This indicates that complexes with low degree of covalency in the $\mathrm{Sn}-\mathrm{O}$ bonds, such as $\left[\mathrm{Sn}\left(\mathrm{H}_{2} \mathrm{O}\right)_{3}\right]^{2+}$, result in high electron density in the anti-bonding Sn-O molecular orbital, weakening the Sn-O bonds, and 
the O-Sn-O bond angle becomes smaller due to increased repulsion between electrons in the antibonding orbitals and the coordinated ligands. With increasing degree of covalency in the Sn-O bond the electron density in the anti-bonding Sn-O molecular orbital decreases allowing shorter Sn-O bonds and larger O-Sn-O bond angles, as in $\left[\mathrm{Sn}(\mathrm{OH})_{3}\right]^{-}$. However, when the degree of covalency increases even more, the electron density in the anti-bonding orbital becomes sufficiently low to allow higher CNs, see Summary.

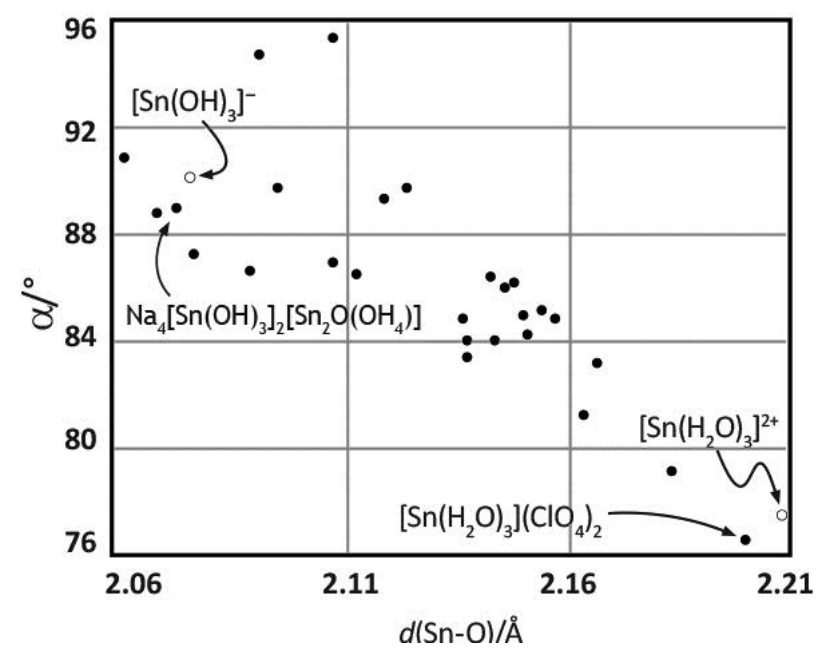

Figure 5. The distribution of mean $\mathrm{Sn}-\mathrm{O}$ distance and their corresponding mean $\mathrm{O}$ Sn-O bond angle $\alpha$ of all reported tin(II) hydrate and solvates (filled circles) listed in the Inorganic Crystal Structure Database (ref. 8) and the Cambridge Structural Database (ref. 7), as compared to the hydrated tin(II) ion in solution and solid state, and the trihydroxostannate(II) anion in aqueous solution and solid state.

\section{The Dimethylsulfoxide Solvated Tin(II) Ion}

The crystal structure of pentakis(dmso)tin(II) perchlorate $\left[\mathrm{Sn}\left(\mathrm{OS}\left(\mathrm{CH}_{3}\right)_{2}\right)_{5}\right]\left(\mathrm{ClO}_{4}\right)_{2}, 2$, shows that tin(II) binds five dmso molecules in square pyramidal fashion, where the square plane of oxygens is on the same side as the axial oxygen making it distorted and clearly affected by the electron density in the anti-bonding orbital, responsible for the large gap in the coordination sphere; the mean $\mathrm{O}_{\mathrm{ax}}-\mathrm{Sn}-\mathrm{O}_{\mathrm{eq}}$ and $\mathrm{O}_{\mathrm{eq}}-\mathrm{Sn}-\mathrm{O}_{\mathrm{eq}}$ angles are 79.4 and $88.0^{\circ}$, respectively, Table 1 . The Sn-O bond distance to the axially coordinated dmso, opposite to the anti-bonding orbital, is markedly shorter, $2.172 \AA$, than those in the equatorial plane, mean $2.343 \AA$. This is the first reported isolated five-coordinate tin(II) compound. The only two previously reported five-coordinate tin(II) complexes with only oxygen donor ligands are in mixed tin(II)/tin(IV) tetrameric compounds with two bridging oxo and eight bridging trifluoroacetato groups. ${ }^{[25,26]}$ In these two compounds, tin(II) has the same kind of distorted square pyramidal configuration as in 2 . The mean Sn-O bond distances in the axial and equatorial positions are 2.14 and $2.45 \AA$, respectively, thus significantly different from the Sn-O distances in 2 . The structure of the $\left[\mathrm{Sn}\left(\mathrm{OS}\left(\mathrm{CH}_{3}\right)_{2}\right)_{5}\right]^{2+}$ 
unit is shown in Figure 6, and its position in the unit cell in Figure S3, selected Sn-O bond distances and O-Sn-O bond angles are given in Table 1, and the .cif file in Table S3 in the Supporting Material section.
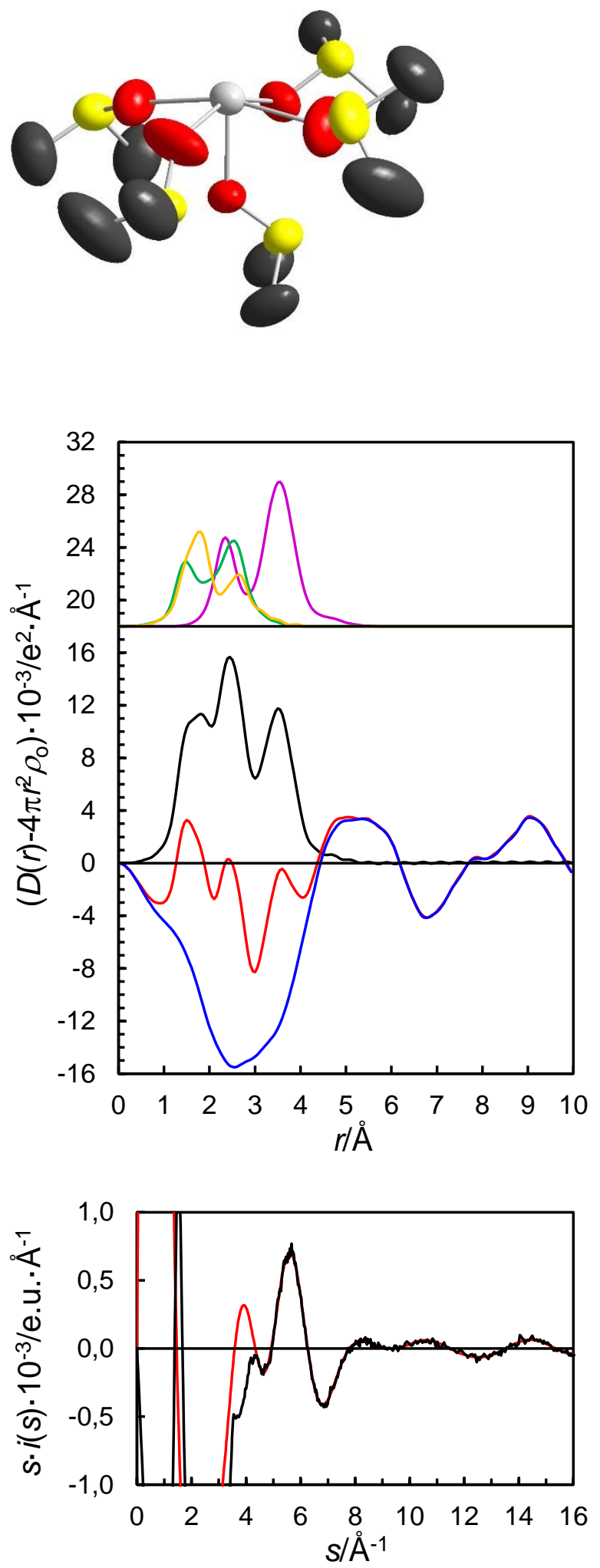

Figure 6. Structure of the $\left[\mathrm{Sn}\left(\mathrm{OS}\left(\mathrm{CH}_{3}\right)_{2}\right)_{5}\right]^{2+}$ unit in $\mathbf{2}$ with a gap covering roughly a hemisphere. Thermal elipsoids (at $40 \%$ probability) are shown for all atoms; methyl hydrogens have been removed for clarity.

Figure 7. (Top) LAXS radial distribution curves for a $1.30 \mathrm{~mol} \cdot \mathrm{dm}^{-3}$ dimethylsulfoxide solution of tin(II) perchlorate. Upper part: Separate model contributions (offset: 18) of the hydrated tin(II) ion (cerise line), the perchlorate ion (brown line) and solvent (green line). (Middle) Experimental RDF: $D(r)-4 \mathrm{p} r^{2} \rho_{\text {o }}$ (red line); sum of model contributions (black line); difference (blue line). (Bottom) Reduced LAXS intensity functions $s \cdot i(s)$ (black line); model $s \cdot i_{\text {calc }}(s)$ (red line). 
The RDF of the LAXS data of the dmso solution of tin(II) trifluoromethanesulfonate reveal three peaks at $1.5,2.35$ and $3.4 \AA$, and a marked shoulder at $1.8 \AA$, Figure 7. The peak at $1.5 \AA$ and the shoulder at $1.8 \AA$ correspond to the intramolecular distances within the dmso molecule and the trifluoromethanesulfonate ion, and the distances at 2.35 and $3.4 \AA$ to the $\mathrm{Sn}-\mathrm{O}$ and $\mathrm{Sn} \cdots \mathrm{S}$ distances in the dmso solvated tin(II) ion, respectively. The structure of the pentakis(dmso)tin(II) ion in $\mathbf{2}$ was used as a starting model for the structure in solution as the observed $\mathrm{Sn}-\mathrm{O}$ bond distance at ca. $2.35 \AA$ fits well with the structure of $\mathbf{2}$, and it is far too long for a lower coordination number, Table $\mathrm{S} 1$. The $\mathrm{Sn}-\mathrm{O}_{\mathrm{eq}}$ and $\mathrm{Sn}-\mathrm{O}_{\mathrm{ax}}$ bond distances were refined to $2.345(12)$ and 2.20(2) $\AA$, respectively, and the corresponding $\mathrm{Sn} \cdots \mathrm{S}_{\mathrm{eq}}$ and $\mathrm{Sn} \cdots \mathrm{S}_{\mathrm{ax}}$ distances to 3.582(8) and 3.38(2) A, respectively, yielding Sn-O-S bond angels of 134(2) and 129(3) ${ }^{\circ}$, respectively. This shows that the structure of the pentakis(dmso)tin(II) ion in $\mathbf{2}$ is maintained in dmso solution. The structure parameters are given in Table 3 and the RDF and fit of experimental LAXS data are shown in Figure 7. Analyses of the XANES region of $\mathbf{2}$ show a very good fit with a fivecoordination with four dmso molecules in the equatorial positions and one in the axial one, and $\mathrm{O}_{\mathrm{ax}}-\mathrm{Sn}-\mathrm{O}_{\mathrm{eq}}$ and $\mathrm{O}_{\mathrm{eq}}-\mathrm{Sn}-\mathrm{O}_{\mathrm{eq}}$ angles of ca. 82 and $90^{\circ}$, respectively, and Figure 4 . The $\mathrm{Sn}-\mathrm{O}$ bond distances are systematically ca. $0.04 \AA$ shorter than in 2 . The non-structural and structural parameters of the XANES fittings are summarized in Table 4.

The reason for the large difference in structure between the hydrated and dmso solvated tin(II) ions is likely the difference in the Sn-O bond characteristics with a larger covalent contribution in dmso causing a lower electron density around tin(II), thereby decreasing the electrostatic repulsion between the anti-bonding orbitals allowing more ligands to bind. The oxygen in dmso has a significantly better ability to form covalent interactions than the oxygen in water seen in the solvent ligands' $D_{\mathrm{S}}$ values, 27 and 18, respectively. ${ }^{[21]}$ The pentakis(dmso)tin(II) ion is the first isolated tin(II) complex with monodentate ligands with a coordination number larger than three; one four-coordinate complex with monodentate ligands has been reported, but that compound has a chain-like structure. ${ }^{[27]}$

\section{The N,N-Dimethylthioformamide Solvated Tin(II) Ion}

The RDF of the LAXS data of the dmtf solution of tin(II) trifluoromethanesulfonate solution reveal three peaks at 1.5, 2.75 and $3.4 \AA$, Figure 8 . The intramolecular distances in dmtf 

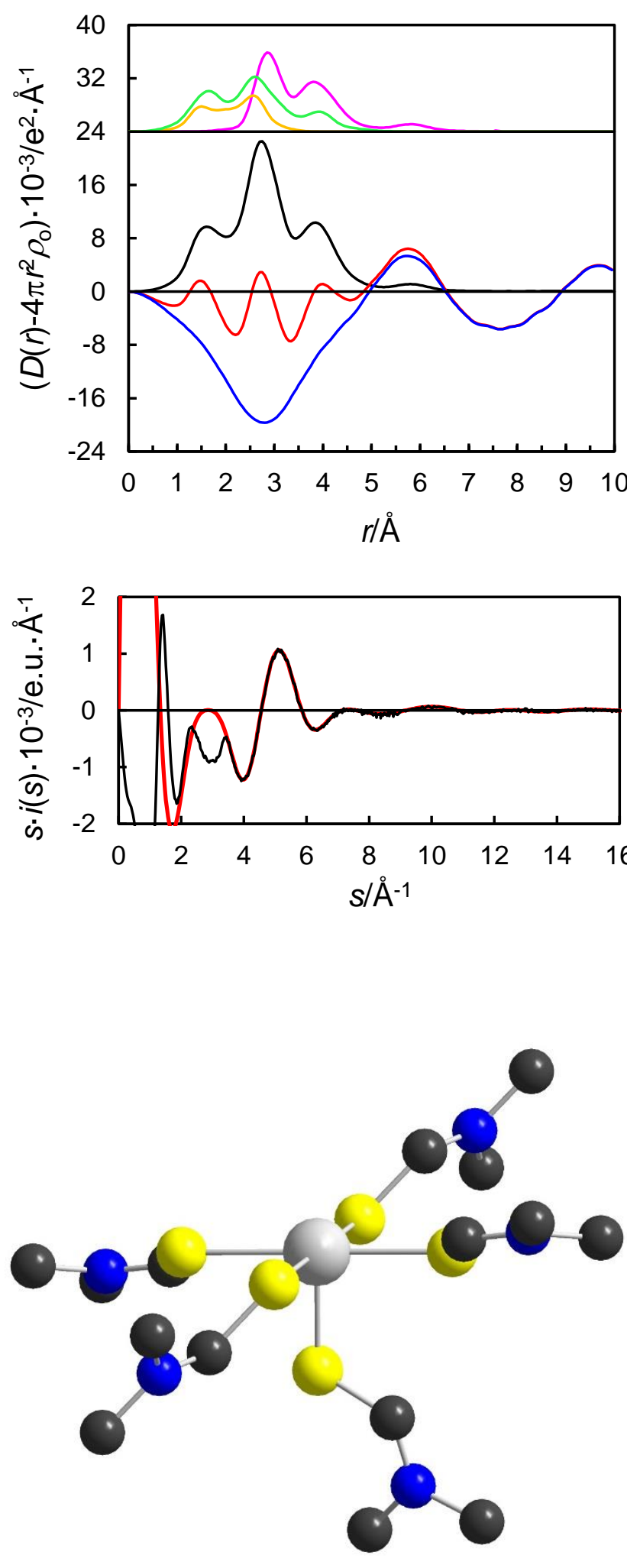

Figure 8. (Top) LAXS radial distribution curves for a $1.00 \mathrm{~mol} \cdot \mathrm{dm}^{-3} \mathrm{~N}, \mathrm{~N}$-dimethylthioformamide solution of tin(II) perchlorate. Upper part: Separate model contributions (offset: 24) of the hydrated tin(II) ion (cerise line), the trifluoromethanesulfonate ion (orange line) and solvent (green line).

(Middle) Experimental RDF: $D(r)-4 \mathrm{p} r^{2} \rho_{\mathrm{o}}$ (red line); sum of model contributions (black line); difference (blue line). (Bottom) Reduced LAXS intensity functions $s \cdot i(s)$ (black line); model $s \cdot i_{\text {calc }}(s)$ (red line).

Figure 9. Proposed structure of the $\left[\mathrm{Sn}\left(\mathrm{SCN}\left(\mathrm{CH}_{3}\right)_{2}\right)_{5}\right]^{2+}$ ion, featuring a hemispherical gap. 
and in the trifluoromethanesulfonate ion give large contributions to all peaks, but the major contribution to the latter two peaks corresponds to the Sn-S and Sn $\cdots \mathrm{C}$ distances in the dmtf solvated tin(II) ion. The best fit of the experimental data was obtained by a five-coordinate model with a similar configuration as the pentakis(dmso)tin(II) ion. The $\mathrm{Sn}-\mathrm{S}_{\mathrm{eq}}$ and $\mathrm{Sn}-\mathrm{S}_{\mathrm{ax}}$ bond distances were refined to 2.898(8) and 2.698(8) $\AA$, respectively, and the corresponding $\mathrm{Sn}^{\cdots} \mathrm{C}_{\mathrm{eq}}$ and $\mathrm{Sn} \cdots \mathrm{C}_{\mathrm{ax}}$ distances to 3.656(16) and 3.51(4) $\AA$, respectively, giving Sn-S-C bond angles of 102.5(1.2) and 104(2) ${ }^{\circ}$, respectively. A proposed model of the pentakis(dmtf)tin(II) ion is shown in Figure 9.

As coordinating solvent dmtf has an even stronger ability to form covalent interactions than dmso with $D_{\mathrm{S}}$ values of 52 and 27, respectively, ${ }^{[21]}$ and a high $\mathrm{CN}$ is therefore expected, but apparently not sufficiently high to form a holo-directed complex. There are five two-coordinate tin(II) complexes with monodentate sulfur donors, albeit anionic, with all featuring a distinct Lshaped S-Sn-S center. The gap extends up to $280^{\circ}$ while the mean Sn-S bond distance is $2.47 \AA$, Table S4. Additionally, there are three three-coordinate structures of tin(II) complexes with monodentate sulfur donor ligands have been reported. In these cases the ligands are anions, two structures with the monodentate phenylthiolate ion, $\mathrm{C}_{6} \mathrm{H}_{5} \mathrm{~S}^{-}$, and one with the thiobenzoate ion, $\mathrm{C}_{6} \mathrm{H}_{5} \mathrm{CS}_{2}{ }^{-}$. For these structures, the tin(II) ion binds the three ligands in pyramidal fashion with a mean Sn-S bond distance of $2.56 \AA$, a mean S-Sn-S bond angle of $91.5^{\circ}$, thus a somewhat larger angle than in the three-coordinate oxygen donor complexes, Tables S1 and S4. For higher coordination numbers, no tin(II) complexes with only monodentate sulfur donor ligands have been reported, Table S4.

\section{Coordination chemistry and ionic radii of $d^{10} s^{2}$ metal ions}

The coordination chemistry of the $\mathrm{d}^{10} \mathrm{~s}^{2}$ metal ions is strongly affected by partially filled antibonding metal-ligand molecule orbitals which may cause a significant gap in the coordination sphere as discussed in the Introduction section. The configurations around the central atom in tin(II) as well as thallium(I), lead(II) and bismuth(III) complexes and compounds in reported solid state structures are summarized in Tables S1 and S5-S7, respectively. This summary shows that all thallium(I) and tin(II) complexes/compounds reported so far in solid state, except SnTe, ${ }^{5}$ display a significant gap in the coordination sphere, i.e. hemi-directed coordination, as well as for lead(II) ${ }^{[24]}$ and bismuth(III) complexes/compounds with low coordination numbers, while those with higher coordination number may be either hemi- or holo-directed, Tables S6 and S7. Hemi- 
directed complexes display a wide bond distance distribution, sometimes several tenths of an Ångström, and the distribution of mean bond distances for complexes and compounds with a certain coordination number is much wider than for any other kind of metal ions; the typical coordination geometries for hemi-directed $\mathrm{d}^{10} \mathrm{~s}^{2}$ metal ions with coordination numbers 2-8 are shown in Figure S4. This makes it not possible to give a well-defined ionic radius for hemidirected $\mathrm{d}^{10} \mathrm{~s}^{2}$ metal ions, where instead a possible ionic radius range can be given, Table 5 . This means also that for the hemi-directed $\mathrm{d}^{10} \mathrm{~s}^{2}$ ions it is not possible to predict the coordination number of the metal ion from the metal-ligand bond distance, which is normally the case for other metal ions. On the other hand, the holo-directed complexes have narrow bond distance distribution, and the spread in the mean bond distances for a certain coordination number is smaller making it possible to give an ionic radius in the same sense as for other metal ions, Table 5.

Table 5. Summary of observed ionic radius ranges for hemi-directed tin(II), thallium(I), lead(II) and bismuth(III) ions for the coordination numbers, CNs, 2-8, and ionic radii for holo-directed lead(II) and bismuth(III) ions for coordination numbers 6 and 8 for solid state structures assuming a radius of oxygen donor ligands to $1.34 \AA$, ref. 29 . * denotes that only a limited number of data is available, see Tables S1, and S5-S7 for details.

\begin{tabular}{lccccccc}
$\mathrm{CN}$ & 2 & 3 & 4 & 5 & 6 & 7 & 8 \\
\hline \multicolumn{2}{l}{ Hemi-directed complexes } & & & & & & \\
Tin(II) & $0.62-0.76$ & $0.74-0.84$ & $0.85-0.97$ & $1.04-1.05^{*}$ & $1.05-1.18$ & & $\sim 1.26^{*}$ \\
Thallium(I) & $1.12-1.39$ & $1.13-1.51$ & $1.30-1.55$ & $1.49-1.57^{*}$ & $1.52-1.67$ & $1.57-1.61^{*}$ & $1.54-1.67$ \\
Lead(II) & $\sim 0.85^{*}$ & $0.88-1.02$ & $0.89-1.10$ & $1.08-1.22$ & $1.17-1.26$ & $1.23-1.34$ & $1.31-1.34^{*}$ \\
Bismuth(III) & $0.69-0.81$ & $0.82-0.96$ & $0.89-1.06$ & $0.99-1.22$ & $1.08-1.21$ & $1.11-1.20$ \\
\hline Holo-directed complexes & & & & & & \\
Lead(II) & & & & & 0.98 & & 1.16 \\
Bismuth(III) & & & & & & & \\
\hline
\end{tabular}

As a consequence of the importance of the bonding character of the $\mathrm{d}^{10} \mathrm{~s}^{2}$ metal-ligand bond, the coordination number of solvates and complexes is independent of the chemical activity of the ligand in solution as shown here for tin(II) in pure solvents and in hyper-alkaline aqueous solution. ${ }^{[19]}$ The hydrated tin(II) and lead(II) ${ }^{[28]}$ ions are hemi-directed three- and six-coordinate 
in aqueous solution, and the hydroxostannate(II) and -plumbate(II) complexes in hyper-alkaline solution are both hemi-directed three-coordinate, ${ }^{[19,30]}$ while hydrated bismuth(III) ion is holodirected eight-coordinate in aqueous solution. ${ }^{[31]}$

\section{Conclusions}

The coordination chemistry of tin(II), and the other $\mathrm{d}^{10} \mathrm{~s}^{2}$ metal ions thallium(I), lead(II) and bismuth(III), is strongly affected by filled or partly filled metal(ns)-ligand(n $p)$ anti-bonding orbitals, which may form large voids in the coordination sphere and especially for complexes with low coordination number. Therefore, the metal-ligand bond character is highly responsible for the coordination number and geometry, with increasing voids with increasing electrostatic character of the metal-ligand bond. Complexes with a void in the coordination sphere, hemidirected, are characterized by very broad bond distance distribution and may have very different mean metal-ligand bond distance within the same coordination number, and without well-defined ionic radii. On the other hand, complexes without a void, holo-directed, have narrow bond distance distribution, and well-defined ionic radii for different coordination numbers can be obtained, Table 5. Prime examples of hemi-directed complexes are the three-coordinated $\left[\mathrm{Sn}\left(\mathrm{H}_{2} \mathrm{O}\right)_{3}\right]^{2+}$ and $\left[\mathrm{Sn}(\mathrm{OH})_{3}\right]^{-}$complexes in acidic and hyper-alkaline aqueous solution, respectively, ${ }^{[19]}$ vide supra. With increasing covalency of the metal-ligand bond the electron density on the anti-bonding orbital decreases allowing higher coordination numbers seen in the five-coordinate dmso and dmtf solvated tin(II) ions. Tin(II) seems to be stable in aqueous solutions over long periods of time while in organic solvents as dmso and dmtf the solvent is slowly reduced and tin(II) oxidized to tin(IV).

\section{Experimental Section}

Solvents. All water used was MilliQ-filtered. Dimethylsulfoxide, $\left(\mathrm{CH}_{3}\right)_{2} \mathrm{SO}$ (Merck), was freshly distilled under vacuum over calcium hydride, $\mathrm{CaH}_{2}$ (Fluka), before use, while $N, N$ dimethylthioformamide, $\left(\mathrm{CH}_{3}\right)_{2} \mathrm{NCHS}$, (Sigma-Aldrich), was used as purchased.

Chemicals. Tin(II) oxide, $\mathrm{SnO}$ (Aldrich), perchloric acid, $\mathrm{HClO}_{4}$ (Fluka), and trifluoromethanesulfonic acid, $\mathrm{CF}_{3} \mathrm{SO}_{3} \mathrm{H}$ (Fluka), were used as purchased.

Preparation of salts. Anhydrous tin(II) trifluoromethanesulfonate, $\mathrm{Sn}\left(\mathrm{CF}_{3} \mathrm{SO}_{3}\right)_{2}$, was prepared by dropwise addition of trifluoromethanesulfonic acid to a slurry of tin(II) oxide under stirring until a clear solution was obtained. The obtained solution was cooled to room temperature and filtered, 
and thereafter put into an oven at $450 \mathrm{~K}$ to boil off water and excess acid. The obtained white powder was ground into a fine powder and stored in oven at $450 \mathrm{~K}$.

Trisaquatin(II) perchlorate, $\left[\mathrm{Sn}\left(\mathrm{H}_{2} \mathrm{O}\right)_{3}\right]\left(\mathrm{ClO}_{4}\right)_{2}$, $\mathbf{1}$, was prepared by dropwise addition of perchloric acid to a slurry of tin(II) oxide under stirring until a clear solution was obtained. The volume of the solution was reduced by evaporation, and the obtained solution was refrigerated for crystallization.

Pentakis(dmso)tin(II) perchlorate, $\left[\mathrm{Sn}\left(\mathrm{OS}\left(\mathrm{CH}_{3}\right)_{2}\right)_{5}\right]\left(\mathrm{ClO}_{4}\right)_{2}, 2$, was prepared by dissolving $1.0 \mathrm{~g}$ 1 (2.7 mmole) in $20 \mathrm{~mL}$ dry acetone and $1.0 \mathrm{~mL}$ 2,2-dimethoxypropane (8.1 mmole) was added, and the solution was stirred for two hours, and thereafter $1.15 \mathrm{~mL}$ dimethylsulfoxide $(16.2$ mmole) was added and the resulting solution was stirred for another 30 minutes. ${ }^{[32]}$ The volume of the solution was reduced to ca. $5 \mathrm{~mL}$ by evaporation, and then refrigerated for crystallization. Preparation of Solutions. The aqueous tin(II) perchlorate solution was prepared by dissolving 1 in $0.1 \mathrm{~mol} \cdot \mathrm{dm}^{-3}$ perchloric acid. The dmso solution of tin(II) perchlorate, and the dmtf solution of tin(II) trifluoromethanesulfonate were prepared by dissolving appropriate amount of $\mathbf{2}$ and anhydrous tin(II) trifluoromethanesulfonate in respective solvent. Composition, density and linear absorption coefficients of the studied solutions are summarized in Table 7. Long-time storage of the tin(II) dmso and dmtf solutions reveal slow reduction of the solvent to dimethyl sulfide and sulfide ions, respectively, and tin(II) was oxidized to tin(IV). It is therefore important to study freshly prepared solutions in solvents which may participate in redox reactions.

Table 7. Compositions (in mol. $\mathrm{dm}^{-3}$ ), densities $(\rho)$, and linear absorption coefficients $(\mu)$ of the aqueous, dimethylsulfoxide (dmso) and $N, N$-dimethylthioformamide (dmtf) solutions used in the LAXS and/or XAFS measurements.

\begin{tabular}{|c|c|c|c|c|c|}
\hline Sample & {$\left[\mathrm{Sn}^{2+}\right]$} & {$\left[\mathrm{X}^{-}\right]$} & [solvent] & $\rho / g \cdot \mathrm{cm}^{-3}$ & $\mu / \mathrm{cm}^{-1}$ \\
\hline $\mathrm{Sn}\left(\mathrm{ClO}_{4}\right)_{2}$ in water ${ }^{\mathrm{a}, \mathrm{b}}$ & 1.700 & 4.400 & 45.028 & 1.456 & 9.45 \\
\hline $\mathrm{Sn}\left(\mathrm{ClO}_{4}\right)_{2}$ in dmso ${ }^{\mathrm{a}, \mathrm{b}}$ & 1.300 & 2.600 & 11.272 & 1.423 & 9.93 \\
\hline $\mathrm{Sn}\left(\mathrm{CF}_{3} \mathrm{SO}_{3}\right)_{2}$ in dmtf a,b & 1.000 & 2.000 & 7.512 & 1.388 & 8.42 \\
\hline
\end{tabular}

${ }^{\mathrm{a}}$ LAXS $\quad{ }^{\mathrm{b}}$ EXAFS

\section{Single-Crystal X-ray Diffraction}

Data were collected on a Bruker SMART CCD $1 \mathrm{k}$ diffractometer at ambient room temperature, Table 7 . The crystals were mounted in glass capillaries, which were sealed by burning 
immediately after mounting. The structures were solved by standard direct methods in the SHELXL 2014/7 program package ${ }^{[33]}$ and refined by full matrix least-squares isotropically on $F^{2}$ and finally in anisotropic approximation on all non-hydrogen atoms, unless noted. Hydrogen atoms were detected in the difference Fourier syntheses and refined using a riding model. All structure solutions were performed with the SHELXL 2014/7 programs in PC version. ${ }^{\text {[33] }}$ Selected crystal and experimental data are summarized in Table 8. The atomic coordinates, bond distances and angles are available in Crystallographic Information Files (CIFs) in the Supplementary Material section, Tables S2 and S3.

\section{XAFS - Data Collection}

Tin K-edge X-ray absorption spectra were recorded at the wiggler beam line 4-1 at the Stanford Synchrotron Radiation Lightsource (SSRL). The EXAFS station was equipped with a Si[220] double crystal monochromator. SSRL operated at 3.0 GeV and a current of 97-100 mA in top up mode. The data collection was performed in transmission mode and at ambient temperature. Higher order harmonics were reduced by detuning the second monochromator crystal to $30 \%$ of maximum intensity at the end of the scans. The solutions were placed in cells with $2 \mathrm{~mm}$ Teflon spacers and $6 \mu \mathrm{m}$ polypropylene foil windows. The energy scale of the X-ray absorption spectra was calibrated by assigning the first inflection point of the K edge of a tin foil to $29198 \mathrm{eV}$. $^{[34]}$ For each sample 3-6 scans were averaged, giving satisfactory data ( $k^{3}$-weighted) in the $k$-range 2$15 \AA^{-1}$. The EXAFSPAK program package was used for the primary data treatment. ${ }^{[35]}$

\section{EXAFS - Data Analysis}

The data analysis was performed by means of the GNXAS code in order to get the best possible splines. The GNXAS code is based on the calculation of the EXAFS signal and a subsequent refinement of the structural parameters. ${ }^{[36,37]}$ The GNXAS method accounts for multiple scattering (MS) paths, with correct treatment of the configurational average of all the MS signals to allow fitting of correlated distances and bond distance variances (Debye-Waller factors). A correct description of the first coordination sphere of the studied complex has to account for asymmetry in the distribution of the ion-solvent distances. ${ }^{[37,38]}$ Therefore the two-body signals associated with the first coordination shells were modeled with $\Gamma$-like distribution functions which depend on four parameters, namely the coordination number $N$, the average distance $R$, the mean-square variation $\sigma$, and the skewness $\beta$; $\beta$ is related to the third cumulant $C_{3}$ through 
the relation $C_{3}=\sigma^{3} \cdot \beta$. It is important to stress that the position of the maximum of the distribution, $R_{\mathrm{m}}$, is different and at shorter distance than the mean distance.

The standard deviations given for the reported refined parameters are obtained from $k^{3}$-weighted least squares refinements of the EXAFS function $\chi(k)$, do not include systematic errors of the measurements. These statistical error estimates provide a measure of the precision of the results and allow reasonable comparisons e.g. of the significance of relative shifts in the distances. However, the variations in the refined parameters, including the shift in the $E_{\mathrm{o}}$ value (for which $k=0$ ), using different models and data ranges, indicate that the absolute accuracy of the distances given for the separate complexes is within \pm 0.005 to $0.02 \AA$ for well-defined interactions. The "standard deviations" given in the text have been increased accordingly to include estimated additional effects of systematic errors.

\section{Large-Angle X-ray Scattering}

A large-angle $\theta-\theta$ diffractometer was used to measure the scattering of Mo K $\alpha$ radiation $(\lambda=0.7107 \AA)$ on the free surface of an aqueous solution of tin(II) perchlorate, and dmso and dmtf solutions of tin(II) trifluoromethanesulfonate. The solutions were contained in a Teflon cuvette inside a radiation shield with beryllium windows. After monochromatization of scattered radiation, by means of a focusing $\mathrm{LiF}$ crystal, the intensity was measured at 450 discrete points in the range $1<\theta<65^{\circ}$ (the scattering angle is $2 \theta$ ). A total of 100,000 counts were accumulated at each angle and the whole angular range was scanned twice, corresponding to a statistical uncertainty of about $0.3 \%$. The divergence of the primary X-ray beam was limited by 1 or $1 / 4^{\circ}$ slits for different $\theta$ regions with some parts of the data overlapping for scaling purposes. All data treatment was carried out by the KURVLR program ${ }^{[39]}$ which has been described in detail previously. ${ }^{[40]}$ The experimental intensities were normalized to a stoichiometric unit of volume containing one tin atom, using the scattering factors $f$ for neutral atoms, including corrections for anomalous dispersion, $\Delta f^{\prime}$ and $\Delta f^{\prime \prime},{ }^{[41]}$ and values for Compton scattering. ${ }^{[42]}$ To receive a better alignment of the intensity function, a Fourier back-transformation was applied to eliminate spurious not related to any interatomic distances peaks below $1.2 \AA$ in the radial distribution function. ${ }^{[43]}$ Least-squares refinements of the model parameters were performed by means of the STEPLR program ${ }^{[44]}$ to minimize the error square sum $U=\Sigma w(s) \cdot\left[i_{\exp }(s)-i_{\text {cal }}(s)\right]^{2}$. 
Table 8. Crystallographic data and structure refinement details for tin(II) compounds $\mathbf{1}$ and 2.

1

2

\begin{tabular}{|c|c|c|}
\hline Formula & $\begin{array}{l}{\left[\mathrm{Sn}\left(\mathrm{H}_{2} \mathrm{O}\right)_{3}\right]\left(\mathrm{ClO}_{4}\right)_{2}} \\
\mathrm{H}_{6} \mathrm{Cl}_{2} \mathrm{O}_{11} \mathrm{Sn}\end{array}$ & $\begin{array}{l}{\left[\mathrm{Sn}(\mathrm{dmso})_{5}\right]\left(\mathrm{ClO}_{4}\right)_{2}} \\
\mathrm{C}_{10} \mathrm{H}_{30} \mathrm{Cl}_{2} \mathrm{O}_{13} \mathrm{~S}_{5} \mathrm{Sn}\end{array}$ \\
\hline$M_{\mathrm{W}}$ & 371.64 & 708.26 \\
\hline Diffractometer system & Bruker Smart CCD & Bruker Smart CCD \\
\hline Radiation, $\lambda / \AA$ & 0.71073 & 0.71073 \\
\hline Crystal system & Hexagonal & Triclinic \\
\hline Space group & $\mathrm{P}_{3}$ (No. 173) & P-1 (No. 2) \\
\hline$a / \AA$ & $7.1492(13)$ & $11.106(2)$ \\
\hline$b / \AA$ & $7.1492(13)$ & $11.456(2)$ \\
\hline$c / \AA$ & $9.861(3)$ & $12.482(3)$ \\
\hline$\alpha /^{\circ}$ & 90 & $66.51(3)$ \\
\hline$\beta l^{\circ}$ & 90 & $81.04(3)$ \\
\hline$y^{\circ}$ & 120 & $89.84(3)$ \\
\hline$V / \AA^{3}$ & $436.5(2)$ & $1435.6(6)$ \\
\hline$T / \mathrm{K}$ & $295(2)$ & $300(2)$ \\
\hline$Z$ & 2 & 2 \\
\hline$D_{\mathrm{c}} / \mathrm{g} \mathrm{cm}^{-1}$ & 2.828 & 1.488 \\
\hline$F^{2}$ & 356 & 716 \\
\hline$\mu / \mathrm{mm}^{-1}$ & 3.587 & 1.488 \\
\hline crystal size/mm & $0.2 \times 0.25 \times 0.3$ & $0.25 \times 0.27 \times 0.32$ \\
\hline$\theta$ range $/^{\circ}$ & $3.29-25.68$ & $1.80-25.02$ \\
\hline index ranges & $-8 \leq h \leq 6$ & $-11 \leq h \leq 13$ \\
\hline & $-8 \leq k \leq 8$ & $-12 \leq k \leq 13$ \\
\hline & $-11 \leq l \leq 12$ & $-14 \leq l \leq 14$ \\
\hline Measured reflections & 2317 & 7318 \\
\hline Unique reflections & $547\left(\mathrm{R}_{\mathrm{int}}=00.0303\right)$ & $3368\left(\mathrm{R}_{\mathrm{int}}=0.0145\right)$ \\
\hline Data/Restraints/Params & $547 / 4 / 53$ & $4989 / 234 / 311$ \\
\hline Goodness of fit & 1.158 & 0.915 \\
\hline Refinement method & \multicolumn{2}{|c|}{ Full-matrix least-sq. $F^{2}$ Full-matrix least-sq. $F^{2}$} \\
\hline Final $R_{1}, \mathrm{w} R_{2}[I>2 \sigma(I)]^{a}$ & $0.0482,0.1117$ & $0.0382,0.0898$ \\
\hline Final $R_{1}, \mathrm{w} R_{2}$ [all data] & $0.0490,0.1129$ & $0.0631,0.0954$ \\
\hline Max. peak/hole e $\AA^{-3}$ & $1.303 /-1.844$ & $0.586 /-0.415$ \\
\hline
\end{tabular}

${ }^{a} R$ values are defined as: $R_{1}=\Sigma \| F_{\mathrm{o}}|-| F_{\mathrm{c}}|| / \Sigma\left|F_{\mathrm{o}}\right|, w R_{2}=\left[\Sigma\left[w\left(F_{\mathrm{o}}{ }^{2}-{F_{\mathrm{c}}}^{2}\right)^{2}\right] / \Sigma\left[w\left(F_{\mathrm{o}}{ }^{2}\right)^{2}\right]\right]^{0.5} ; \mathrm{dmso}=$ $\left(\mathrm{CH}_{3}\right)_{2} \mathrm{SO}$ 


\section{XANES - Data analysis}

The analysis of the XANES data was carried out with the MXAN code. ${ }^{[45]}$ MXAN uses the muffin-tin (MT) approximation for the shape of the potential and a complex optical potential, based on the local density approximation of the self-energy of the excited photoelectron. The MT radii have been chosen on the basis of previous investigations and are 1.5, 1.0, 0.8, 0.7 and 0.21 $\AA$ for tin, sulfur, oxygen, carbon and hydrogen, respectively. ${ }^{[45]}$ The self-energy is calculated in the framework of the Hedin-Lundqvist (HL) scheme. Only the real part of the HL potential is used in the calculation, while inelastic losses are accounted for by MXAN using a phenomenological approach based on the convolution of the theoretical spectrum with a Lorentizian function having an energy-dependent width of the form $\Gamma_{\mathrm{tot}}(E)=\Gamma_{\mathrm{c}}+\Gamma_{\mathrm{mfp}}(E)$. The constant part, $\Gamma_{\mathrm{c}}$, includes the core-hole lifetime, while the energy-dependent term, $\Gamma_{\mathrm{mfp}}(E)$, represents all the intrinsic and extrinsic inelastic processes. The function $\Gamma_{\mathrm{mfp}}(E)$ is zero below an onset energy, $E_{\mathrm{s}}$, and begins to increase from a value, $A_{\mathrm{s}}$, following the universal functional form of the mean free path in solids. Both the onset energy $E_{\mathrm{s}}$ and the jump $A_{\mathrm{s}}$ are introduced in the $\Gamma_{\text {tot }}(E)$ function via an arctangent functional to avoid discontinuities and to simulate the electronhole pair excitations. Their numerical values are derived at each computational step (i.e., for each geometric configuration) on the basis of a Monte Carlo fit. The experimental resolution is taken into account by a Gaussian convolution. The minimization procedures have been carried out starting from the X-ray structures of triaquatin(II) perchlorate and pentakis(dmso)tin(II) perchlorate, see cif files in the Supporting Material section. Least-squares fits of the experimental data in the space of the structural and non-structural parameters are achieved by minimizing the residual function defined as

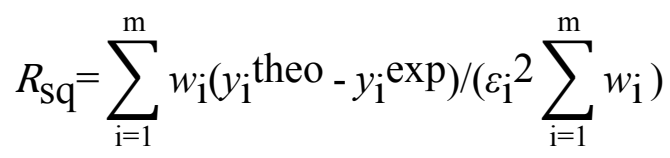

where $m$ is the number of data points, $y_{\mathrm{i}}^{\text {theo }}$ and $y_{\mathrm{i}}^{\text {exp }}$ are the theoretical and experimental values of absorption, respectively, $\varepsilon_{\mathrm{i}}$ is the individual error in the experimental data set, and $w_{\mathrm{i}}$ is a statistical weight. For $w_{\mathrm{i}}=1$ (constant), the square residual function, $R_{\mathrm{sq}}$, becomes the statistical $w^{2}$ function. Here, we assumed a constant experimental error, $\varepsilon=1.2 \%$, for the whole experimental data set. Six non-structural parameters have been optimized, namely the Fermi energy level, $E_{\mathrm{F}}$, the core-hole lifetime $\Gamma_{\mathrm{c}}$, the experimental resolution $\Gamma_{\exp }$, the threshold energy $E_{\mathrm{o}}$, and the energy and amplitude of the plasmon, $E_{\mathrm{s}}$ and $A_{\mathrm{s}}$, respectively. 


\section{Acknowledgments}

We gratefully acknowledge the Swedish Research Council for financial support. Portions of this research were carried out at the Stanford Synchrotron Radiation Lightsource (SSRL), which is acknowledged for the allocation of beam-time and laboratory facilities. SSRL is a national user facility operated by Stanford University on behalf of the US Department of Energy, Office of Basic Energy Services. The SSRL Structural Molecular Biology Program is supported by the Department of Energy, Office of Biological and Environmental Research, and by the National Institute of Health, National Center for Research Resources, Biomedical Technology Program.

\section{Supporting Material}

Supporting information available: Additional information as noted in the text is available, free of charge, via the internet at http://....

\section{References}

[1] a/ N. V. Sidgwick, The Electronic Theory of Valency, Clarendon Press, Oxford, UK, 1927; b/ N. V. Sidgwick, H. M. Powell, Proc. R. Soc. (London) 1940, 176, 153-180.

[2] A. Walsh, G. A. Watson, J. Phys. Chem. B 2005, 109, 18868-18875.

[3] M. W. Stoltzfus, P. M. Woodward, R. Seshadri, J.-H. Klepeis, B. Bursten, Inorg. Chem. 2007, 46, 3839-3850.

[4] A. Walsh, D. J. Payne, R. G. Edgell, G. A. Watson, Chem. Soc. Rev. 2011, 40, 4455-4463.

[5] a/ R. F. Bis, J. R. Dixon, J. Appl. Phys. 1969, 40, 1918-1921; b/ R. F. Brebrick, J. Phys. Chem. Solids 1971, 32, 551-562; c/ K. Dovletov, N. K. Samakhotina, A. V. Anikin, A. Ashirov, Inorg. Mater. 1975, 11, 1036-1038; d/ U. Sondermann, J. Magnetism Magnetic Mater. 1976, 2, 216-222; e/ Y. Sternberg, N. Yellin, S. Cohen, L. Ben Dor, J. Solid State Chem. 1982, 43, 364-367; f/ E. I. Rogacheva, G. V. Gorne, S. A. Laptev, A. V. Arinkin, T. B. Vesiene, J. Solid State Chem. 1982, 43, 364-367; J. Phys. Soc. Jpn. 1988, 57, 3820-3823; g/ I. V. Dubrovin, L. D. Budennaya, I. B. Mizetskaya, E. V. Sharkina, Inorg. Mater. 1983, 19, 1603-1606; h/ S. A. Movsum-Zade, M. R. Allasov, A. A. Movsum-Zade, E. S. Guseinova, Russ. J. Inorg. Chem. 1984, 29, 1194-1196; i/ R. T. Yakimova, E. P. Trifonova, L. Karagiozov, S. Petrov, Cryst. Res. Technol. 1984, 19, K109-K112; j/ S. A. Stavrianidis, A. A. Kutsiya, G. A. Keiyan, R. A. Markeliya, R. R. Shvangiradze, Inorg. Mater. 1984, 20, 1520-1521; k/ A. Ashirov, A. P. Gurshumov, K. Dovletov, N. A. Mamedov, Russ. J. Inorg. 
Chem. 1986, 31, 729-731; 1/ I. V. Dubrovin, L. D. Budennaya, I. B. Mizetskaya, E. V. Sharkina, Inorg. Mater. 1986, 22, 515-520; m/ N. I. Dzyubenko, E. I. Rogacheva, G. V. Gorne, N. K. Zhigarev, A. B. Ivanova, Inorg. Mater. 1988, 24, 1486-1488; n/ T. S. Yeoh, S. G. Teoh, H. K. Fun, J Phys. Soc. Jpn. 1988, 57, 3820-3823; o/ R. Marx, K. J. Range, J. LessCommon Met. 1989, 155, 49-59; p/ P. Bauer Pereira, I. Sergueev, S. Gorsse, J. Dadda, E. Müller, R. P. Hermann, Physica Status Solidi B - Basic Solid State Physics 2013, 250, 13001307.

[6] L. Shimoni-Livny, J. P. Glusker, C. W. Bock, Inorg. Chem. 1998, 37, 1853-1867, and references therein.

[7] Mudring, A.-V. in Inorganic Chemistry in Focus III, ed. Meyer, G.; Naumann, D.; Wesemann, L., Wiley-VCH Verlag, Weinheim, Germany 2006.

[8] Mudring, A.-V.; Rieger, F. Inorg. Chem. 2005, 44, 6240-6243.

[9] Walsh, A.; Watson, G. W. J. Solid State Chem. 2005, 178, 1422-1428.

[10] Mudring, A.-V. Eur. J. Inorg. Chem. 2007, 882-890, and references therein.

[11] F. H. Allen, Acta Crystallogr., Sect. B 2002, 58, 380-388.

[12] Inorganic Crystal Structure Database 1.4.6 (release: 2016-1); FIZ/NIST.

[13] G. Johansson, H. Ohtaki, Acta Chem. Scand. 1973, 27, 643-660.

[14] T. Yamaguchi, O. Lindqvist, T. Cleason, J. B. Boyce, Chem. Phys Lett. 1982, 93, 528-532.

[15] L. H. V. Lim, T. S. Hofer, A. B. Pribil, B. M. Rode, J. Phys. Chem. B 2009, 113, 43724378 .

[16] T. S. Hofer, A. B. Pribil, B. R. Randolf, B. M. Rode, J. Am. Chem. Soc. 2005, 127, 1423114238.

[17] E. Hennings, H. Schmidt, M. Köhler, W. Voigt, Acta Crystallogr., Sect. E. 2014, 70, 474476.

[18] R. S. Tobias, Acta Chem. Scand. 1958, 12, 198-223.

[19] E. G. Bajnóczi, E. Czeglédi, E. Kuzmann, Z. Hamonnay, G. Dombi, P. Forgo, O. Berkesi, I. Pálinkó, G. Peintler, P. Sipos, I. Persson, I. Dalton Trans. 2014, 43, 17971-17979.

[20] H. G. von Schnering, R. Nesper, H. Pelshenke, Z. Anorg Allg. Chem. 1983, 499, 117-129.

[21] M. Sandström, I. Persson, P. Persson, Acta Chem. Scand. 1990, 44, 653-675.

[22] P. D’Angelo, D. Lucarelli, S. Della Longa, M. Benfatto, J. L. Hazeman, A. Feis, G. Smulevich, A. Ilari, A. Bonamore, A. Boffi, Biophys. J. 2004, 86, 3882-3892. 
[23] P. D’Angelo, A. Lapi, V. Migliorati, A. Arcovito, M. Benfatto, O. M. Roscioni, W. MeyerKlaucke, S. Della Longa, Inorg. Chem. 2008, 47, 9905-9918.

[24] R. D. Shannon, Acta Crystallogr., Sect. A 1976, 32, 751-767

[25] A. V. Zabula, A. S. Filatov, M. A. Petrukhina, J. Cluster Sci. 2010, 21, 361-370.

[26] T. Birchall, J. P. Johnson, J. Chem. Soc., Dalton Trans. 1981, 69-73.

[27] T. J. Boyle, T. M. Alam, M. A. Rodriguez, C. A. Zechmann, Inorg. Chem. 2002, 41, 25742582.

[28] I. Persson, K. Lyczko, D. Lundberg, L. Eriksson, A. Płaczek, Inorg. Chem. 2011, 50, 10581072 ;

[29] J. K. Beattie, S. P. Best, B. W. Skelton, A. H. White, J. Chem. Soc., Dalton Trans. 1981, 2105-2111.

[30] E. G. Bajnóczi, I. Pálinkó, T. Körtvéleysi, S. Bálint, I. Bakó, P. Sipos, I. Persson, Dalton Trans. 2014, 43, 17539-17543.

[31] J. Näslund, I. Persson, M. Sandström, Inorg. Chem. 2000, 39, 4012-4021.

[32] K. Starke, J. Inorg. Nucl. Chem. 1959, 11, 77-78.

[33] G. M. Sheldrick, SHELX 2014/7: Program for Crystal Structure Refinement; University of Göttingen, Göttingen, Germany, 2014.

[34] A. Thompson, D. Attwood, E. Gullikson, M. Howells, K.-J. Kim, J. Kirz, J. Kortright, I. Lindau, Y. Liu, P. Pianetta, A. Robinson, J. Scofield, J. Underwood, G. Williams, H. Winick, X-ray data booklet, Lawrence Berkley National Laboratory, 2009.

[35] G. N. George, I. F. Pickering, EXAFSPAK - A suite of Computer Programs for Analysis of X-ray absorption spectra, Stanford Synchrotron Radiation Laboratory, Stanford, CA, 1995. http://www-ssrl.slac.stanford.edu/ george/exafspak/exafs.htm

[36] A. Filipponi, A. Di Cicco, C. R. Natoli, Phys. Rev. B. 1995, 52, 15122-15134.

[37] A. Filipponi, J. Phys.: Condens. Matter, 1994, 6, 8415-8427.

[38] L. Hedin, B. I. Lundqvist, J. Phys. C: Solid State Phys., 1971, 4, 2064-2083.

[39] G. Johansson, M. Sandström, Chem. Scr. 1973, 4, 195-198.

[40] C. M. V. Stålhandske, I. Persson, M. Sandström, E. Kamienska-Piotrowicz, Inorg. Chem. 1997, 36, 3174-3182.

[41] International tables for X-ray Crystallography, Kynoch Press: Birmingham, U.K., 1974, Vol. 4.

[42] D. T. Cromer, J. Chem. Phys. 1969, 50, 4857-4859. 
[43] H. A. Levy, M. D. Danford, A. H. Narten, Data Collection and Evaluation with an X-ray Diffractometer Designed for the Study of Liquid Structure, Technical Report ORNL-3960; Oak Ridge National Laboratory: Oak Ridge, TN, 1966.

[44] M. Molund, I. Persson, Chem. Scr. 1985, 25, 197-197.

[45] M. Benfatto, S. Della Longa, C. R. Natoli, J. Synchrotron Radiat. 2003, 10, 51-57. 